\title{
International Psychogeriatrics Paper of the year 2015: the use of modern technology to tackle an old challenge - improving the diagnosis of delirium in the hospital setting
}

In 2014, International Psychogeriatrics (IPG) for the first time introduced a "paper of the month" category as part of the 25th year's milestone celebrations. Papers of the month were chosen through an internal selection process by the IPG editorial team. Each month, the seven editors ranked suitable accepted papers from the categories "original research articles" and "reviews" according to scientific quality and clinical relevance. Each paper of the month was accompanied by a brief commentary written by one of the IPG editors, one of the reviewers for the paper, or an international expert on the specific topic of the paper. From the 12 papers of the month, an IPG paper of the year was selected after a ranking process involving three independent expert reviewers. Last year's winner was by Gilbert et al. on "The association of traumatic brain injury with rate of progression of cognitive and functional impairment in a population-based cohort of Alzheimer's disease: the Cache County Dementia Progression Study" (Gilbert et al., 2014; Lautenschlager and Ames, 2015). In 2015, the IPG editorial team did it all over again which led to ten papers of the months for 2015, as the special issues in July and October were not included in this process. The ten papers of the month for 2015 included eight that were original research articles and two reviews. As in 2014, the 2015 papers of the month again covered a diverse variety of psychogeriatric topics. Eight of the ten papers reported on cognition, cognitive deterioration, cognitive disorders or dementia, whereas the two others focused on delirium. The former discussed issues such as a provisional consensus clinical and research definition of agitation (Cummings et al., 2015), medication development for agitation and aggression in Alzheimer's disease (Soto et al., 2015), awareness of memory deficits (Lehrner et al., 2015), psychotic symptoms in frontotemporal dementia (Landqvist et al., 2015), determinants of cognitive deterioration in late-life depression (Riddle et al., 2015), an activity of daily living tool for the diagnosis of mild cognitive impairment (De Vriendt et al., 2015), intentional and unintentional poisoning in dementia
(Mitchell et al., 2015) and prevalence and incidence of dementia in indigenous populations (Warren et al., 2015). The latter included a comparison of delirium diagnoses in elderly medical inpatients using different classification criteria (Adamis et al., 2015) and using smartphone technology to detect attentional deficits in delirium (Tieges et al., 2015). As in 2014, the ten papers were truly international with authors coming from Argentina, Australia, Austria, Belgium, Canada, France, Greece, Ireland, Sweden, the UK, and the USA.

This year, our three independent reviewers were Prof. Alexander Kurz from Germany, Prof. Martin Orrell from the UK, and Prof. Nancy Pachana from Australia and the highest ranked paper and, therefore, paper of the year 2015 was "Development of a smartphone application for the objective detection of attentional deficits in delirium" by Zoe Tieges, Antaine Stiohairt, Katie Scott, Klaudia Suchorb, Alexander Weir, Stuart Parls, Susan Shenkin, and Alasdair MacLullich from the UK (Tieges et al., 2015).

The feedback from the reviewers included the comments that Tieges et al. "provide a fresh and intelligent solution for an old problem: how to test attention at the bedside reliably? This is an example of how neuropsychological assessment can take advantage of modern technology. Similar apps should be provided for the testing of memory and executive functioning." and [that] "the novel approach could assist in the diagnosis of delirium by providing a rapid and accurate assessment of inattention via a smartphone app."

Ken Rockwood wrote an excellent commentary about the paper of the year, which appeared in the same issue (Rockwood, 2015).

The IPG editorial team is excited that our second paper of the year uses a modern $21 \mathrm{st}$ century approach aiming to improve the diagnosis of delirium, one of the most common, but also difficult to recognize psychogeriatric conditions, in the hospital setting. There is no doubt that we will see increasingly more often publications investigating the potential benefit of modern technology for prevention, diagnosis, and management of 
psychogeriatric syndromes and disorders. We hope the work by Tieges et al. will inspire IPA members and IPG readers to embrace investigating young technologies as potential aids for tackling mental health challenges for older people.

We thank our three independent reviewers, congratulate the authors of the paper of the year 2015 and look forward to the IPG papers of the month of 2016 .

\section{Conflict of interest}

NT Lautenschlager is the Editor-in-Chief of International Psychogeriatrics and therefore this editorial was assigned to one of the Deputy Editors of International Psychogeriatrics for the editorial review and approval process.

NiCOLA T. LAUTENSCHLAGER ${ }^{1,2,3}$ AND DAVID AMES ${ }^{1,4}$, on behalf of the Editorial Team of International Psychogeriatrics Editor-in-Chief and Immediate Past Editor-in-Chief

${ }^{1}$ Academic Unit for Psychiatry of Old Age, Department of Psychiatry, The University of Melbourne,

Melbourne, Australia

${ }^{2}$ NorthWestern Mental Health, Melbourne Health, Melbourne, Australia

${ }^{3}$ School of Psychiatry and Neurosciences and WA

Centre for Health \& Ageing, The University of Western

Australia, Perth, Australia

${ }^{4}$ National Ageing Research Institute, Parkville, Australia

\section{References}

Adamis, D., Rooney, S., Meagher, D., Mulligan, O. and McCarthy, G. (2015). A comparison of delirium diagnosis in elderly medical inpatients using the CAM, DRS-R98, DSM-IV and DSM-5 criteria. International Psychogeriatrics, $27,883-889$.

Cummings, J. et al. (2015). Agitation in cognitive disorders: International psychogeriatric association provisional consensus clinical and research definition. International Pyschogeriatrics, 27, 7-17.
De Vriendt, P., Mets, T., Petrovic, M. and Gorus, E. (2015). Discriminative power of the advanced activities of daily living (a-ADL) tool in the diagnosis of mild cognitive impairment in an older population. International Psychogeriatrics, 27, 1419-1427.

Gilbert, M., Snyder, C., Corcoran, C., Norton, M. C., Lyketsos, C. G. and Tschanz, J. T. (2014). The association of traumatic brain injury with rate of progression of cognitive and functional impairment in a population-based cohort of Alzheimer's disease: the cache county dementia progression study. International Psychogeriatrics, 26, 1593-1601.

Landqvist, M. W., Gustafson, L., Passant, U. and Englund, E. (2015). Psychotic symptoms in frontotemporal dementia: a diagnostic dilemma? International Psychogeriatrics, 27, 529-530.

Lautenschlager, N. T. and Ames, D. (2015). International Psychogeriatrics paper of the year 2014: a new tradition and the first candidate for a 2024 paper of the decade? International Psychogeriatrics, 27, 527-528.

Lehrner, J. et al. (2015). Awareness of memory deficits in subjective cognitive decline, mild cognitive impairment, Alzheimer's disease and Parkinson's disease. International Psychogeriatrics, 27, 357-366.

Mitchell, R. J., Harvey, L. A., Brodaty, H., Draper, B. and Close, J. C. (2015). Dementia and intentional and unintentional poisoning in older people: a 10 year review of hospitalization records in New South Wales, Australia. International Psychogeriatrics, 27, 1757-1768.

Riddle, M., McQuoid, D. R., Potter, G. G., Steffens, D. C. and Taylor, W. D. (2015). Disability but not social support predicts cognitive deterioration in late-life depression. International Psychogeriatrics, 27, 707-714.

Rockwood, K. (2015). Bringing delirium into the $21^{\text {st }}$ century: will physicians get the app out? International Psychogeriatrics, 27, 1247-1249.

Soto, M. et al. (2015). Medication development for agitation and aggression in Alzheimer disease: review and discussion of recent randomized clinical trial design. International Psychogeriatrics, 27, 181-197.

Tieges, Z. et al. (2015). Development of a smartphone application for the objective detection of attentional deficits in delirium. International Psychogeriatrics, 27, 1251-1262.

Warren, L. A., Shi, Q., Young, K., Borenstein, A. and Martiniuk, A. (2015). Prevalence and incidence of dementia among indigenous populations: a systematic review. International Psychogeriatrics, 27, 19591970. 